\title{
WORKSHOP BODY MAPPING UNTUK MENINGKATKAN SELF-ESTEEM PADA ORANG DENGAN HIV
} (ODHIV)

\author{
Hartono $^{1^{\star}}$, Frans Judea Samosir ${ }^{2}$ \\ Program Studi Kesehatan Masyarakat Universitas Prima Indonesia
}

*Email: hartonoboy31@gmail.com

\begin{abstract}
ABSTRAK
Hingga Maret 2019 dilaporkan ada 338.363 kasus orang yang teinfeksi HIV di Indonesia. ODHIV mengalami tantangan secara fisik dan mental diakibatkan stigma dari diri dan masyarakat. Tujuan dari penelitian ini adalah untuk mengetahui pengaruh dari pelaksanaan intervensi workshop body mapping dalam meningkatkan self-esteem (harga diri) pada ODHIV. Penelitian ini menggunakan quasi-experimental one group pretest- posttest design. Subjek penelitian adalah 30 orang dengan HIV yang direkrut menggunakan teknik purposive sampling. Pretest dan Postest berupa kuesioner self-esteem diberikan kepada peserta sebelum dan sesudah workshop untuk mengumpulkan data yang dibutuhkan. Lalu, data diuji menggunakan paired sample t-test. Hasil dari penelitian menunjukkan bahwa tidak terdapat pengaruh workshop body mapping dalam meningkatkan self-esteem pada ODHIV.
\end{abstract}

Kata Kunci : body mapping, self-esteem, ODHIV

\begin{abstract}
As of March 2019 there were 338,363 reported cases of people infected with HIV in Indonesia. PLHIV experiences challenges physically and mentally due to stigma from themselves and society. The purpose of this study was to determine the effect of the implementation of body mapping workshop intervention in increasing self-esteem on PLHIV. This study used a quasi-experimental one group pretest-posttest design. The research subjects were 30 People Living with HIV who were recruited by using purposive sampling technique. Pretest and posttest in the form of self-esteem questionnaires were given to participants before and after the workshop to collect the required data. Then, the data were analyzed by using the paired sample t-test. The results of the study showed that there was no effect of body mapping workshop in increasing self-esteem among PLHIV.
\end{abstract}

\section{Keywords : body mapping, self-esteem, PLHIV}

\section{PENDAHULUAN}

Diperkirakan sekitar 35 juta orang telah terinfeksi HIV di seluruh dunia pada tahun 2013 (World Health Organization, 2016). Di tahun 2014, mereka yang terinfeksi bertambah sehingga angka orang dengan HIV (ODHIV) meningkat menjadi 36.9 juta kasus (UNAIDS, 2015). Di Indonesia sendiri, hingga Maret 2019 dilaporkan ada 338.363 kasus orang yang teinfeksi HIV (Kementerian Kesehatan RI, 2019). Hal ini tentunya menjadi tantangan bagi pemerintah untuk menanggulangi dampak negatif baik yang dirasakan masyarakat secara umum dan ODHIV itu sendiri.

ODHIV mengalami tantangan seperti kekuatan fisik mereka yang menurun dan masalah kesehatan mental yang diakibatkan stigma dari masyarakat. Hal ini telah berlangsung sejak kasus pertama kali ditemukan di tahun 1981. Orang yang hidup dengan HIV mengalami kerugian karena stigma yang dapat mempengaruhi kualitas hidup mereka. Stigma dapat bermanifestasi dalam berbagai bentuk seperti prasangka dan diskriminasi di berbagai negara dan dalam budaya yang berbeda baik secara sosial maupun intrapersonal (Mahajan et al., 2008). Akibatnya, stigma berkontribusi terhadap hambatan untuk intervensi, pencegahan, pengobatan, dan perawatan yang efektif untuk ODHA (International Center for Research on Women, 2015). Stigma memicu pasien untuk merasa rendah diri; terdemotivasi untuk menjalani kehidupan yang sehat; dan mengalami rasa benci dan stres (Rahmati-Najarkolaei et al., 2010). Lebih lanjut, masyarakat cenderung memandang infeksi HIV sebagai kondisi yang hanya terjadi pada kelompok populasi tertentu seperti pengguna narkoba dan kaum gay karena mereka terlibat dalam perilaku 'tidak bermoral' (Tsai, Bangsberg and Weiser, 2013). Bentuk-bentuk stigma ini menghasilkan risiko gangguan emosional yang lebih besar seperti depresi, rasa malu, rendah diri, dan rasa putus asa. Orang yang telah terinfeksi oleh HIV dapat menginternalisasi status HIV mereka dan merasa bahwa mereka layak mendapatkan penyakit tersebut dan menerima label negatif yang pada akhirnya diyakininya sebagai kebenaran (Bennett et al., 2016; Tsai, Bangsberg and Weiser, 2013; Herek, Capitanio and Widaman, 2002; Lee, Kochman and Sikkema, 2002).

Stigma yang terinternalisasi dapat didefinisikan sebagai konsep diri yang negatif, selfesteem (harga diri) yang rendah (merasa rendah 
diri terhadap orang lain), merasa malu dan meyakini pemikiran yang salah tentang diri sendiri ketika hidup dengan HIV (Audet et al., 2013; Bennett et al., 2016). Stigma yang diinternalisasi secara negatif memengaruhi kesehatan, kesejahteraan dan perilaku ODHIV, serta secara negatif memengaruhi kepatuhan terhadap pengobatan dan perawatan medis (Earnshaw et al., 2014; Ware, Wyatt and Tugenberg, 2006). Fenomena ini menyoroti pentingnya untuk melakukan intervensi yang efektif untuk membantu ODHIV meningkatkan kualitas hidup mereka.

Sudah ada intervensi yang dilakukan sejauh ini dalam meningkatkan kualitas hidup ODHIV terkhusus untuk meningkat self-esteem. Salah satu intervensi yang dapat memfasilitasi peningkatan self-esteem ODHIV dalam menghadapi stigma adalah terapi seni. Terapi seni diakui sebagai alat yang efektif untuk meningkatkan komunikasi dan harga diri (Bitonte and De Santo, 2014; Samosir, Hansen and Ringdahl, 2018). Salah satu bentuk terapi seni yang telah digunakan untuk membantu ODHIV menceritakan kisah mereka adalah body mapping (peta tubuh), yang pada awalnya dilakukan di Afrika Selatan (Solomon, 2007). Body mapping didefinisikan sebagai kegiatan berbasis seni untuk menciptakan citra tubuh seukuran manusia yang disebut peta tubuh menggunakan gambar, lukisan, warna, gambar, dan kata-kata untuk memvisualisasikan secara kreatif berbagai aspek kehidupan seseorang, pengalaman tubuh, keadaan emosi dan mental, dan cerita seseorang tentang dunia tempat tinggalnya. Body mapping secara terapeutik membantu orang untuk menceritakan kisah mereka lewat gambar, simbol, atau pola yang mereka masukkan ke dalam peta tubuh mereka. Makna peta tubuh seseorang adalah kepunyaan yang membuatnya karena pentingnya peta tubuh hanya dapat disampaikan melalui pengalaman pembuatnya (Gastaldo et al., 2012; Art2Be, 2020; Botha, 2017). Penelitian ini mengadaptasi dan menerapkan workshop body mapping untuk membantu ODHIV di Medan meningkatkan self-esteemnya. Penelitian ini berbeda dengan penelitian terdahulu dalam hal pendekatan desain dan jumlah sampel penelitian. Peneliti tidak menemukan literatur terkait penggunaan body mapping sebagai intervensi bagi
ODHIV dilakukan di Indonesia. Oleh sebab itu, peneliti ingin melihat bagaimana pendekatan secara kuantitatif kuasi eksperimen dapat melihat perbedaan skor self-esteem 30 ODHIV sebelum dan sesudah workshop body mapping. Oleh karena itu, tujuan dari penelitian ini adalah untuk mengetahui bagaimana pengaruh dari pelaksanaan intervensi workshop body mapping dalam meningkatkan self-esteem pada ODHIV.

\section{METODE}

Penelitian ini menggunakan rancangan kuasieksperimen dengan satu kelompok pratespaskates (quasi-experimental one group pretestposttest design): $\mathrm{O} 1$ - X - O2 (O1 adalah pretest, X adalah workshop body mapping, $\mathrm{O} 2$ adalah posttest). Kekuatan desain adalah peneliti tidak perlu menemukan kelompok ODHIV lain untuk perbandingan (Royse, 2010). Partisipan dalam penelitian ini adalah 30 Orang Dengan HIV (ODHIV) di kota Medan yang dijangkau dengan menggunakan teknik purposive sampling. Workshop diadakan di Medan Plus jalan Jamin Ginting Pasar VII No. 45 selama tiga hari berturutturut. Setiap harinya workshop dihadiri oleh 10 orang, 8 orang dan 12 orang dan partisipan mengikuti workshop body mapping selama 8 jam per hari. Hal ini dilakukan untuk menghindari kontak keramaian selama pandemic COVID-19 dan untuk memastikan kualitas workshop terjaga dengan baik. Dengan demikian, peneliti kemudian menilai perubahan self-esteem sebelum dan setelah intervensi body mapping pada kelompok peserta yang sama. Untuk mengumpulkan data, peneliti menggunakan skala Coopersmith Self Esteem Inventory (Gunawan, 2018). Setelah itu uji paired sample t-test dilakukan untuk mengukur perbedaan pretest dan posttest self-esteem kelompok intervensi (McDonald, 2014). Analisis data menggunakan software SPSS.

\section{HASIL \\ Karakteristik Partisipan}

Berikut adalah karakteristik partisipan yang meliputi usia, gender, orientasi seksual, tahun mengetahui status HIV dan rasa malu (shame).

Tabel 1. Distribusi Frekuensi Karakteristik Partisipan

\begin{tabular}{ccc}
\hline Karakteristik Partisipan & Jumlah (Orang) & Persentase (\%) \\
\hline Usia & 3 & \\
$17-21$ & 9 & 10.00 \\
$22-26$ & 8 & 20.00 \\
$27-31$ & 6 & 26.67 \\
$32-36$ & 3 & 20.00 \\
$37-41$ & 1 & 10.00 \\
$42-46$ & 24 & 3.33 \\
\hline Gender & & 80.00 \\
Male & &
\end{tabular}




\begin{tabular}{ccc} 
Female & 4 & 13.30 \\
Transpuan & 2 & 6.70 \\
\hline Orientasi Seks & 15 & 50.00 \\
Gay & 9 & 30.00 \\
Biseksual & 6 & 20.00 \\
Heteroseksual & 1 & \\
Tahun Status HIV & 2 & 3.33 \\
2012 & 1 & 6.67 \\
2015 & 6 & 3.33 \\
2016 & 3 & 20.00 \\
2017 & 8 & 10.00 \\
2018 & 9 & 26.67 \\
2019 & & 30.00 \\
2020 & 4 & \\
Rasa Malu & 2 & 13.33 \\
Sangat Tidak Malu & 6 & 6.67 \\
Tidak Malu & 10 & 20.00 \\
Netral & 8 & 33.33 \\
Malu & & 26.67 \\
Sangat Malu & & \\
\hline
\end{tabular}

Tabel 1 menunjukkan bahwa usia mayoritas partisipan adalah pada rentang $22-26$ tahun yakni sebanyak 9 orang $(20 \%)$ dan hanya satu orang yang berusia pada rentang $42-46$ tahun. Jumlah laki-laki merupakan gender yang terbanyak yakni sebanyak 24 orang (80\%). Sedangkan partisipan yang mengidentifikasikan dirinya transpuan adalah sebanyak dua orang $(6,7 \%)$. Untuk orientasi seks, workshop ini diikuti mayoritas oleh partisipan yang mengidentifikasi diri sebagai non heteroseksual yakni sebanyak 24 orang (80\%). Sedangkan heteroseksual sebanyak enam orang (20\%). Partisipan yang mengetahui status HIV nya mayoritas di tahun 2020 yakni sebanyak 9 orang (30\%). Sedangkan yang paling lama adalah tahun 2012 yakni satu orang $(13,33 \%)$. Untuk rasa malu (shame) terhadap dirinya, partisipan mengakui memiliki rasa malu sebanyak 18 orang $(60 \%)$ sedangkan tidak malu sebanyak enam orang (20\%).

\section{Self-Esteem pada ODHIV}

Tabel berikut ini menampilkan kategori selfesteem dengan jumlah partisipan sebelum dan setelah mengikuti workshop body mapping.

\section{Tabel 2. Distribusi Frekuensi Self-Esteem Sebelum Mendapat Intervensi}

\begin{tabular}{ccc}
\hline Self-esteem & Jumlah (orang) & Persentase \\
\hline Tinggi & 13 & $43 \%$ \\
Rendah & 17 & $57 \%$ \\
\hline
\end{tabular}

Sumber: Data Primer, 2020

Berdasarkan tabel 2 dapat diketahui bahwa partisipan mayoritas memiliki self-esteem yang rendah sebanyak 17 orang (57\%). Sedangkan partisipan yang memiliki sel-esteem yang tinggi ada sebanyak 13 orang (43\%).

Tabel 3. Distribusi Frekuensi Self-Esteem Setelah Mendapat Intervensi

\begin{tabular}{ccc}
\hline Self-esteem & Jumlah (orang) & Persentase \\
\hline Tinggi & 10 & $33 \%$ \\
Rendah & 20 & $67 \%$ \\
\hline
\end{tabular}

Sumber: Data Primer, 2020

Berdasarkan tabel 3 dapat diketahui bahwa setelah mengikuti workshop, partisipan mayoritas memiliki self-esteem yang rendah sebanyak 20 orang $(67 \%)$. Sedangkan partisipan yang memiliki self-esteem yang tinggi ada sebanyak 10 orang
(33\%). Hal ini sangat berbeda dengan ekspektasi peneliti bahwa diharapkan setelah mengikuti workshop peserta akan lebih menunjukkan peningkatan skor self-esteem. 
Tabel 4. Uji Paired Sample T-Test untuk Self-esteem

\begin{tabular}{|c|c|c|c|c|c|}
\hline \multirow{3}{*}{ Self-esteem } & \multicolumn{2}{|c|}{ Sebelum } & \multicolumn{2}{|c|}{ Sesudah } & \multirow[b]{2}{*}{$p$-value } \\
\hline & $\mathbf{N}$ & Mean & $\mathbf{N}$ & Mean & \\
\hline & 30 & 18,13 & 30 & 17,93 & 0.071 \\
\hline
\end{tabular}

Sumber: Data Primer, 2020

Tabel 4 menunjukkan hasil uji paired sample t-test untuk mengukur perbedaan skor pretest dan posttest self-esteem kelompok intervensi. Diketahui bahwa sesudah mengikuti workshop body mapping, partisipan mengalami penurunan nilai rata-rata self-esteem dari 18,13 menjadi 17,93. Hasil uji-t juga menunjukkan nilai yang tidak signifikan yakni $\mathrm{p}=0,071$ yang bermakna bahwa workshop body mapping tidak berpengaruh terhadap self-esteem ODHIV.

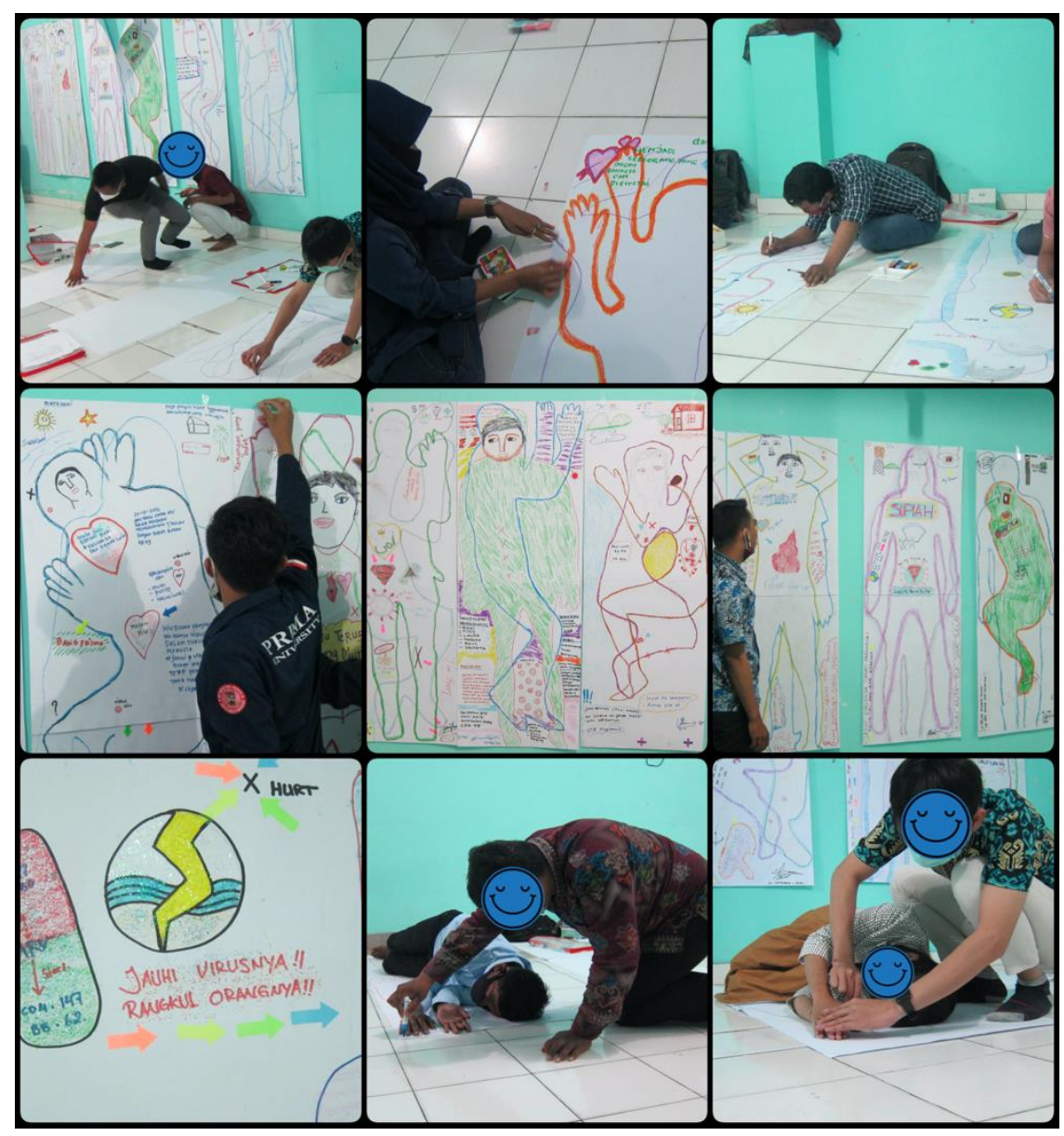

Gambar 1. Workshop Body Mapping

\section{PEMBAHASAN}

Sejalan dengan hasil di atas, penelitian ini menunjukkan bahwa workshop body mapping tidak memiliki pengaruh dalam meningkatkan selfesteem pada ODHIV. Hasil penelitian ini sejalan dengan temuan dari penelitian Samosir, Hansen and Ringdahl (2018) yang menunjukkan tidak ada pengaruh yang signifikan secara kuantitatif pemberian workshop body mapping terhadap selfesteem pada ODHIV. Namun yang menarik adalah secara kualitatif, peserta menunjukkan rasa kepuasaan yang tinggi terhadap workshop dengan menyatakan bahwa workshop tersebut merupakan ruang aman bagi mereka untuk mengekspresikan perasaan dan pikiran serta mendapatkan teman baru. Peserta workshop dalam penelitian tersebut juga menyatakan bahwa mereka merasakan meningkatnya rasa kepercayaan diri, seni advokasi dan merasakan adanya dukungan. Hal ini semakin memperkuat asumsi peneliti bahwa penelitian yang menggunakan workshop body mapping sebagai suatu intervensi, sebaiknya menggunakan pendekatan mixed method (kuantitatif dan kualitatif) untuk mendapatkan informasi dan data yang integratif misalnya melalui wawancara.

Hal ini juga didukung oleh penelitian yang menggunakan pendekatan kualitatif dalam menggali efek intervensi yang dirasakan oleh 
peserta workshop seperti yang dilakukan oleh Nöstlinger, Loos and Verhoest (2015). Hasil dari penelitian mereka adalah workshop body mapping merupakan intervensi yang efektif untuk memberdayakan ODHIV dalam mengatasi stress terkait HIV serta dapat meningkatkan self-esteem (Nöstlinger, 2015). Sedangkan penelitian yang dilakukan oleh Fuster-Ruizdeapodaca, Molero and Ubillos (2016) menunjukkan bahwa intervensi berupa training yang berkesinambungan kepada ODHIV menunjukkan kemampuan mereka untuk mengatasi stigma dan mendapatkan dampak positifnya terhadap kualitas hidup mereka. Hasil penelitiannya juga menunjukkan penurunan skor persepsi stigma, peningkatan self-efficacy untuk mengatasi stigma, dan peningkatan self-esteem dan kualitas hidup.

Menilik dari temuan penelitian ini dan membandingkannya dengan penelitian terdahulu, maka peneliti dapat menjabarkan keterbatasan yang dimiliki sehingga mempengaruhi hasil yang diharapkan. Kegiatan workshop ini dilakukan dari pagi hingga sore hari selama delapan jam dengan istirahat satu jam sehingga hal ini dapat mempengaruhi kondisi menjadi tidak cukup kondusif di penghujung hari bagi partisipan untuk mengisi kuesioner self-esteem secara fokus. Partisipan terlihat tidak konsentrasi dalam mengisi lembar kuesioner. Ini juga dapat menjadi pertimbangan untuk penelitian berikutnya untuk menyesuaikan kuesioner dengan pernyataanpernyataan yang lebih singkat dan mudah dipahami. Penelitian ini juga tidak dapat menjelaskan fenomena internal yang dirasakan partisipan setelah mengikuti workshop body mapping. Oleh sebab itu, wawancara mendalam dan diskusi kelompok terpadu untuk merefleksikan apa yang dialami mereka terkait self-esteem dapat menjadi pertimbangan bagi penelitian berikutnya. Dalam penelitian ini, peneliti juga tidak melakukan evaluasi lanjutan dari segi waktu untuk melihat efek jangka panjang dari intervensi terhadap selfesteem partisipan.

\section{KESIMPULAN}

Penggunaan workshop body mapping sebagai intervensi dalam meningkatkan selfesteem ODHIV adalah suatu hal yang masih dapat dilakukan sesuai temuan penelitian-penelitian terdahulu. Namun dalam penelitian ini, setelah dilakukan uji statistik melalui uji-t, diperoleh bahwa p-value 0,071 $(>0,05)$ yang berarti tidak ada pengaruh workshop body mapping dalam meningkatkan self-esteem pada ODHIV.

\section{SARAN}

Penelitian selanjutnya disarankan menggunakan desain penelitian yang berbeda yakni mixed method untuk menggali variable yang diukur secara kuantitatif dan kualitatif. Sebaiknya durasi worshop juga dapat divariasikan sesuai kebutuhan untuk mencegah rasa lelah seharian dan memperkuat kualitas berbagi di ruangan yang sama; misalnya menjadikannya minimal dua kali pertemuan.

\section{ACKNOWLEDGEMENT}

Terima kasih kami ucapkan kepada Direktorat Riset dan Pengabdian Masyarakat - Direktorat Jenderal Penguatan Riset dan Pengembangan Kementerian Riset, Teknologi, dan Pendidikan Tinggi Republik Indonesia.

\section{DAFTAR PUSTAKA}

Art2Be, 2020. Body Mapping. [online] Available at: <https://www.pinterest.cl/pin/4293197769482 06709/> [Accessed 1 Jul. 2020].

Audet, C.M., McGowan, C.C., Wallston, K.A. and Kipp, A.M., 2013. Relationship between HIV Stigma and Self-Isolation among People Living with HIV in Tennessee. PLOS ONE, $8(8)$.

Bennett, D.S., Traub, K., Mace, L., Juarascio, A. and O'Hayer, C.V., 2016. Shame among people living with HIV: A literature review. AIDS Care - Psychological and Socio-Medical Aspects of AIDS/HIV, 28(1), pp.87-91.

Bitonte, R.A. and De Santo, M., 2014. Art therapy: An underutilized, yet effective tool. Mental Illness, 6(1), pp.18-19.

Botha, C.S., 2017. Using metaphoric bodymapping to encourage reflection on the developing identity of pre-service teachers. South African Journal of Education, 37(3).

Earnshaw, V.A., Lang, S.M., Lippitt, M., Jin, H. and Chaudoir, S.R., 2014. HIV Stigma and Physical Health Symptoms: Do Social Support, Adaptive Coping, and/or Identity Centrality Act as Resilience Resources? AIDS and Behavior, [online] 19(1), pp.41-49. Available at: <https://link.springer.com/article/10.1007/s104 61-014-0758-3> [Accessed 27 Oct. 2020].

Fuster-Ruizdeapodaca, M.J., Molero, F. and Ubillos, S., 2016. Evaluación de una intervención dirigida a reducir el impacto del estigma en las personas con VIH capacitándolas para afrontarlo. Anales de Psicologia, [online] 32(1), pp.39-49. Available at:

<https://revistas.um.es/analesps/article/view/a nalesps.32.1.192121/186851> [Accessed 9 Dec. 2020].

Gastaldo, D., Magalhães, L., Carrasco, C. and Davy, C., 2012. Body-Map Storytelling as Research: Methodological considerations for telling the stories of undocumented workers through body mapping. [online] Available at: <http://www.> [Accessed 27 Oct. 2020].

Gunawan, E.F., 2018. Hubungan Antara Harga Diri Dan Penalaran Moral Pada Remaja Akhir. Skripsi Universitas Sanata Dharma. 
Universitas Sanata Dharma.

Herek, G.M., Capitanio, J.P. and Widaman, K.F., 2002. HIV-related stigma and knowledge in the United States: Prevalence and trends, 1991-1999. American Journal of Public Health, 92(3), pp.371-377.

International Center for Research on Women, 2015. Stigma and Discrimination.

Kementerian Kesehatan RI, 2019. SIHA Online.

Lee, R.S., Kochman, A. and Sikkema, K.J., 2002. Internalized stigma among people living with HIV-AIDS. AIDS and Behavior, 6(4), pp.309319.

Mahajan, A.P., Sayles, J.N., Patel, V.A., Remien, R.H., Sawires, S.R., Ortiz, D.J., Szekeres, G. and Coates, T.J., 2008. Stigma in the HIV/AIDS epidemic: a review of the literature and recommendations for the way forward. AIDS (London, England), 22 Suppl 2.

McDonald, J.H., 2014. Handbook of Biological Statistics (3rd ed.).

Nöstlinger, C., Loos, J. and Verhoest, X., 2015. Coping with HIV in a culture of silence: Results of a body-mapping workshop. AIDS Research and Human Retroviruses, [online] 31(1), pp.47-48. Available at: <http://www.liebertpub.com/doi/10.1089/aid.2 014.0316> [Accessed 27 Oct. 2020].

Rahmati-Najarkolaei, F., Niknami, S., Aminshokravi, F., Bazargan, M., Ahmadi, F., Hadjizadeh, E. and Tavafian, S.S., 2010.
Experiences of stigma in healthcare settings among adults living with HIV in the Islamic Republic of Iran. Journal of the International AIDS Society, 13(1), pp.27-27.

Samosir, F.J., Hansen, N. and Ringdahl, B.A., 2018. Process and Outcome Evaluation of ILiving with Xr: A Body Mapping Workshop in the Time of HIV and AIDS. In: Proceedings of the 2nd Public Health International Conference (PHICo 2017). [online] pp.177185. Available at: <https://www.atlantispress.com/proceedings/phico-17/25897439>.

Solomon, J., 2007. Living with ' $X$ ': A body mapping journey of living with HIV and AIDS.

Tsai, A.C., Bangsberg, D.R. and Weiser, S.D., 2013. Harnessing Poverty Alleviation to Reduce the Stigma of HIV in Sub-Saharan Africa. PLoS Medicine, 10(11).

UNAIDS, 2015. AIDS by the numbers 2015.

Ware, N.C., Wyatt, M.A. and Tugenberg, T., 2006. Social relationships, stigma and adherence to antiretroviral therapy for HIV/AIDS. AIDS Care - Psychological and Socio-Medical Aspects of AIDS/HIV, 18(8), pp.904-910.

World Health Organization, 2016. Global Health Observatory (GHO) data - HIVIAIDS. 